\title{
Volitional assessment of respiratory muscle strength
}

\author{
J.W. Fitting
}

ABSTRACT: Volitional assessment of respiratory muscle strength. J.W. Fitting.

Respiratory muscle weakness may induce dyspnoea, secretion retention and respiratory failure. Assessing respiratory muscle strength is mandatory in neuromuscular diseases and in case of unexplained dyspnoea. A step by step approach is recommended, starting with simple volitional tests. Using spirometry, respiratory muscle weakness may be suspected on the basis of an abnormal flowvolume loop or a fall of supine vital capacity. When normal, maximal inspiratory and expiratory pressures against a near complete occlusion exclude significant muscle weakness, but low values are more difficult to in-

\begin{abstract}
terpret. Sniff nasal inspiratory pressure is a useful alternative because it is easy and it eliminates the problem of air leaks around the mouthpiece in patients with neuromuscular disorders. The strength available for coughing is easily assessed by measuring peak cough flow. In most cases, these simple non invasive tests are sufficient to confirm or to eliminate significant respiratory muscle weakness and help the timely introduction of ventilatory support or assisted cough techniques. In a minority of patients, a more complete evaluation is necessary using non volitional tests like cervical magnetic stimulation of phrenic nerves.

Monaldi Arch Chest Dis 2012; 77: 1, 19-22.
\end{abstract}

Keywords: Diaphragm, Respiratory Muscles, Strength, Sniff, Cough.

Respiratory Division, Lausanne University Hospital, Lausanne, Switzerland.

Correspondence: Prof. Jean-William Fitting, Service de Pneumologie, CHUV 1011 Lausanne, Switzerland; e-mail: jean-william.fitting@chuv.ch

Assessment of respiratory muscles is warranted in suspected or confirmed neuromuscular disorders and in case of unexplained dyspnoea. A step by step work-up is indicated, starting with simple and non invasive tests and completed in a minority of cases with more invasive and expensive procedures. The aims of this article are to summarize the simple tests of respiratory muscle strength and to delineate the advantages and limitations of each procedure. First line tests include volitional tests such as spirometry, maximal static pressures, maximal sniff pressures, and peak cough flow.

\section{When respiratory muscles should be tested?}

Assessing respiratory muscle strength is warranted in some situations because respiratory muscle weakness may induce dyspnoea in the absence of pulmonary disease, or may aggravate dyspnoea in case of pre-existing lung disease. Assessment of respiratory muscle strength is particularly indicated in case of suspected or established neuromuscular disorder, and in case of dyspnoea remaining unexplained after an initial cardiopulmonary work-up. The clinician should be aware of clinical manifestations of respiratory muscle weakness, such as a history of progressive dyspnoea, orthopnoea, morning headache, daytime excessive somnolence, repeated chest infections. On clinical examination, one may observe rapid shallow breathing, abdominal paradox, contraction of accessory neck muscles, weak contraction of abdominal muscles on coughing, or generalized amyotrophy.
At the onset of disease, these clinical clues may easily be overlooked.

\section{Case 1}

A 57 years old business manager, former smoker, began to complain of dyspnoea on exertion, particularly when hiking or swimming. His lung function was first unremarkable: $F E V_{1} 87 \%$ predicted, FVC $87 \%$ predicted, total lung capacity (TLC) 89\% predicted. Over the next two years, dyspnoea progressively increased during walking, speaking and lying supine, and the patient lost 15 $\mathrm{kg}$ of body weight. He was submitted to an extensive work-up: methacholine bronchial provocation test, thoracoabdominal CT scan, oesogastroscopy, colonoscopy, bronchoscopy, cardiac evaluation, and eventually psychiatric evaluation, all found to be normal. When referred two years later to a pulmonary clinic, his respiratory rate was 30/min and prominent contraction of accessory neck muscles was observed. The $F E V_{1}$ was $62 \%$ predicted, $F V C$ $55 \%$ predicted, TLC $75 \%$ predicted. Maximal inspiratory and expiratory pressures were very low and a diagnosis of motor neurone disease was finally established. The patient benefited from non invasive ventilation and was symptomatically improved for several months.

\section{Spirometry}

Standard spirometry can provide useful hints of a possible respiratory muscle weakness. It is worth looking at the flow-volume loop during a 
forced expiratory and inspiratory manoeuvre. In case of respiratory muscle weakness, one may note several anomalies: a slower increase of expiratory flow, a reduced and smoothed peak expiratory flow, an abrupt premature termination of exhalation, and a reduced peak inspiratory flow [1]. A simple spirometer also allows to measure vital capacity in different body positions. When compared to sitting values, the supine vital capacity changes little, decreasing on average by $8 \%$. A fall of vital capacity greater than $25 \%$ in the supine position is a reliable sign of diaphragm weakness, showing a sensitivity of $79 \%$ and a specificity of $90 \%$ [2].

\section{Maximal static pressures}

In subjects with good collaboration and coordination, the maximal static pressures measured at the mouth represent the best physiological assessment of respiratory muscle strength. The test requires a pressure recorder and a mouthpiece. The maximal pressure sustained for 1 second is recorded during either a maximal inspiratory effort for maximal inspiratory pressure $\left(\mathrm{P}_{\mathrm{I}} \max \right)$ or a maximal expiratory effort for maximal expiratory pressure $\left(\mathrm{P}_{\mathrm{E}} \max \right)$ against a near complete occlusion. A small air leak is left open to eliminate the participation of facial muscles. The best value of at least 3 trials is retained [3]. Portable devices for measuring $\mathrm{P}_{\mathrm{I}} \max$ and $\mathrm{P}_{\mathrm{E}} \max$ are available at a relatively low price.

The $\mathrm{P}_{\mathrm{I}}$ max is usually measured at residual volume (RV) and $\mathrm{P}_{\mathrm{E}}$ max at TLC, where the highest values are obtained. However, maximal pressures measured at RV and at TLC reflect both respiratory muscle action and passive recoil of the respiratory system. An alternative consists in measuring these pressures at functional residual capacity (FRC), where they solely reflect inspiratory or expiratory muscle strength. Reference values are available for maximal pressures measured at RV, TLC, and FRC [4]. The main limitation of maximal static pressures relates to the difficulty to perform the manoeuvres. Thus, the effort is often submaximal and the range for normal values is wide. Another limitation lies in the air leaks that occur around the mouthpiece in case of neuromuscular diseases. As a consequence, low values are often difficult to interpret, as they can result from true muscle weakness, from a submaximal effort, or from air leaks. Taking these uncertainties into consideration, it is generally admitted that a $\mathrm{P}_{\mathrm{I}} \max$ and a $\mathrm{P}_{\mathrm{E}} \max >70 \mathrm{~cm} \mathrm{H}_{2} \mathrm{O}$ in women and $>80 \mathrm{~cm}$ $\mathrm{H}_{2} \mathrm{O}$ in men eliminate a significant respiratory muscle weakness $[5,6]$.

\section{Sniff transdiaphragmatic pressure}

The sniff manoeuvre is an interesting alternative for subjects experiencing difficulty to perform the maximal static pressures. A brisk sniff is a natural effort that is easily executed by most individuals. The specific assessment of diaphragm strength requires an invasive procedure with catheter systems to measure gastric pressure (Pga) and oesophageal pressure (Poes). The transdiaphragmatic pressure (Pdi) is the pressure difference across the diaphragm and reflects the contractile force of this muscle: Pdi = Pga - Poes. The peak Pdi measured during a maximal sniff manoeuvre from FRC (sniff Pdi) is the best volitional test for diaphragm strength. The best value of at least 10 trials is considered. Sniff Pdi values $>80 \mathrm{~cm} \mathrm{H}_{2} \mathrm{O}$ in women and $>100 \mathrm{~cm} \mathrm{H}_{2} \mathrm{O}$ in men eliminate a significant weakness of the diaphragm $[3,7]$.

\section{Sniff nasal inspiratory pressure}

The sniff nasal inspiratory pressure (SNIP) is a simple and non invasive test of global inspiratory muscle strength. It consists of measuring peak nasal pressure in one occluded nostril during a maximal sniff performed from FRC through the contralateral open nostril. During the sniff, the nasal valve of the patent nostril collapses and the pressure measured beyond the collapsed segment closely reflects intrathoracic pressure and, therefore, inspiratory muscle strength [8]. The measurement of SNIP is particularly useful in patients with neuromuscular disorders with facial muscle weakness because it obviates the use of a mouthpiece $[9,10]$. The best value of at least 10 trials is considered. Reference values have been established for SNIP in adults [4] and children [11, 12]. SNIP values $>60 \mathrm{~cm} \mathrm{H}_{2} \mathrm{O}$ in women and $>70 \mathrm{~cm} \mathrm{H}_{2} \mathrm{O}$ in men eliminate a significant weakness of inspiratory muscles [3]. The SNIP and the $\mathrm{P}_{\mathrm{I}}$ max are complementary tests of inspiratory muscle strength, and the highest pressure of either test should be considered. Portable devices allowing the measurement of SNIP, $\mathrm{P}_{\mathrm{I}} \max$ and $\mathrm{P}_{\mathrm{E}} \max$ are available.

\section{Case 2}

A 50 years old agricultural worker, current smoker, complained of a sudden pain in the left shoulder. Within days, he noticed dyspnoea on exertion and a marked orthopnoea which prevented him to sleep in the supine position. A chest radiograph showed an ascent of both hemidiaphragms, predominantly on the left side. The lung function tests showed a slight obstructive ventilatory defect: $F E V_{1} 74 \%$ predicted, FVC $88 \%$ predicted, $F E V_{1} / F V C 68 \%$. The vital capacity was $3.88 \mathrm{l}$ in the sitting position and dropped to $1.36 \mathrm{l}$ in the supine position (-65\%). The $P_{I} \max$ was 29 $\mathrm{cm} \mathrm{H}_{2} \mathrm{O}$ (27\% predicted) and the SNIP $27 \mathrm{~cm} \mathrm{H}_{2} \mathrm{O}$ (24\% predicted), whereas the $P_{E}$ max was $80 \mathrm{~cm}$ $\mathrm{H}_{2} \mathrm{O}(61 \%$ predicted $)$. The significant fall of supine vital capacity and the low values of $P_{I}$ max and SNIP confirmed a severe diaphragmatic weakness. A neurological examination established the diagnosis of neuralgic amyotrophy (Parsonage-Turner syndrome), an acute inflammatory brachial neuropathy which can lead to diaphragmatic paralysis [13]. In spite of a normal $\mathrm{PaCO}_{2}$, the patient was nevertheless provided with nocturnal non invasive ventilation which allowed him to regain a normal sleep. 
Table 1. - Non volitional tests of respiratory muscle strength (Values excluding significant respiratory muscle weakness)

\begin{tabular}{lcc}
\hline & Females & Males \\
\hline Inspiratory muscles & & \\
$\mathrm{P}_{\mathrm{I}} \max \left(\mathrm{cm} \mathrm{H}_{2} \mathrm{O}\right)$ & $>70$ & $>80$ \\
$\mathrm{SNIP}\left(\mathrm{cm} \mathrm{H}_{2} \mathrm{O}\right)$ & $>60$ & $>70$ \\
Sniff Pdi $\left(\mathrm{cm} \mathrm{H}_{2} \mathrm{O}\right)$ & $>80$ & $>100$ \\
\hline Expiratory muscles & & \\
$\mathrm{P}_{\mathrm{E}}$ max $\left(\mathrm{cm} \mathrm{H}_{2} \mathrm{O}\right)$ & $>70$ & $>80$ \\
$\mathrm{PCF}(1 /$ min $)$ & & \\
$8-10$ years & $>200$ & $>200$ \\
$11-13$ years & $>300$ & $>300$ \\
$>13$ years & $>350$ & $>350$ \\
\hline
\end{tabular}

$\mathrm{P}_{\mathrm{I}}$ max: maximal inspiratory pressure; SNIP: sniff nasal inspiratory pressure; sniff Pdi: sniff transdiaphragmatic pressure; $\mathrm{P}_{\mathrm{E}}$ max: maximal expiratory pressure; $\mathrm{PCF}$ : peak cough flow.

\section{Peak cough flow}

A functional cough is vital to eliminate airway secretions and other materials. Normal values of $\mathrm{P}_{\mathrm{E}}$ max exclude a significant weakness of expiratory muscles and are usually associated with a normal cough function. However, low $\mathrm{P}_{\mathrm{E}}$ max values are difficult to interpret and may not reliably reflect the efficacy of cough [6]. The peak expiratory flow can be measured during a vigorous cough effort and is called the peak cough flow (PCF). It is measured either with a peak-flow meter or with a pneumotachograph. The best of 4 to 7 trials is considered. Normal values of PCF are $>350 \mathrm{l} / \mathrm{min}$ in the adult. Reference values have also been developed for children and adolescents [14]. The PCF has been specifically developed for testing cough function in patients with neuromuscular disorders. Patients with PCF values $<2701 / \mathrm{min}$ are at risk of secretion retention and respiratory failure in case of pulmonary infection, and those with PCF values $<160 \mathrm{l} / \mathrm{min}$ are totally unable to clear their airways [15]. Monitoring of PCF is helpful to decide when manual and/or instrumental cough assistance is to be instituted.

\section{Case 3}

A 56 years old man suffering from progressive multiple sclerosis manifested severe generalized muscle weakness. He was dyspnoeic while speaking or eating, and reported occasional airway aspirations. His chief complaints were an impaired sleep because of a frequent nocturnal cough, and constant daytime fatigue. On examination, a weak contraction of abdominal muscles was felt during volitional cough. The lung function tests showed: $F E V_{1} 36 \%$ predicted, FVC $36 \%$ predicted, FEV I IFVC 80\%, TLC $88 \%$ predicted, RV $187 \%$ predicted. The $P_{I}$ max was $32 \mathrm{~cm}_{2} \mathrm{O}$ (28\% pre- dicted), SNIP $44 \mathrm{~cm} \mathrm{H}_{2} \mathrm{O}$ (39\% predicted), and $\mathrm{P}_{E}$ $\max 30 \mathrm{~cm} \mathrm{H}_{2} \mathrm{O}$ (21\% predicted). The PCF was 110 l/min, confirming non-functional cough. Arterial blood gases were normal, obviating the need for non invasive ventilation. He was provided with a mechanical insufflation-exsufflation device (Cough Assist ${ }^{\mathrm{TM}}$ ) for assisting cough at home. He used it regularly every evening to clear his airways. From then on, he regained a quiet undisturbed sleep and felt more refreshed during daytime.

\section{Conclusions}

Respiratory muscle weakness may induce dyspnoea and secretion retention, and may result in potentially lethal respiratory failure. A common error is to fail to recognize the role of respiratory muscles in these circumstances, which may delay the introduction of non invasive ventilation or of assisted cough techniques. Respiratory muscle weakness will only be diagnosed if respiratory muscles are tested. Simple and non invasive tests are available, starting with the simple spirometry. Inexpensive and portable devices allow to measure volitional maximal and sniff pressures. Most often, these simple tests are sufficient to confirm or to exclude significant respiratory muscle weakness. In case of doubt, non volitional tests are necessary, like magnetic phrenic nerve stimulation which is performed in specialized centres [16].

\section{References}

1. Vincken WG, Elleker MG, Cosio MG. Flow-volume loop changes reflecting respiratory muscle weakness in chronic neuromuscular disorders. Am J Med 1987; 83: 673-80.

2. Fromageot C, Lofaso F, Annane D, et al. Supine fall in lung volumes in the assessment of diaphragmatic weakness in neuromuscular disorders. Arch Phys Med Rehabil 2001; 82: 123-8.

3. ATS/ERS Statement on respiratory muscle testing. Am J Respir Crit Care Med 2002; 166: 518-624.

4. Uldry C, Fitting JW. Maximal values of sniff nasal inspiratory pressure in healthy subjects. Thorax 1995; 50: 371-5.

5. Polkey MI, Green M, Moxham J. Measurement of respiratory muscle strength. Thorax 1995; 50: 1131-5.

6. Man WD, Kyroussis D, Fleming TA, et al. Cough gastric pressure and maximum expiratory mouth pressure in humans. Am J Respir Crit Care Med 2003; 168: 714-7.

7. Miller JM, Moxham J, Green M. The maximal sniff in the assessment of diaphragm function in man. Clin Sci (Lond) 1985; 69: 91-6.

8. Heritier F, Rahm F, Pasche P, et al. Sniff nasal inspiratory pressure. A noninvasive assessment of inspiratory muscle strength. Am J Respir Crit Care Med 1994; 150: 1678-83.

9. Stefanutti D, Benoist MR, Scheinmann P, et al. Usefulness of sniff nasal pressure in patients with neuromuscular or skeletal disorders. Am J Respir Crit Care Med 2000; 162: 1507-11.

10. Fitting JW, Paillex R, Hirt L, et al. Sniff nasal pressure: a sensitive respiratory test to assess progression of amyotrophic lateral sclerosis. Ann Neurol 1999; 46: 887-93. 
11. Stefanutti D, Fitting JW. Sniff nasal inspiratory pressure. Reference values in Caucasian children. Am J Respir Crit Care Med 1999; 159: 107-11.

12. Rafferty, GF, Leech S, Knight L, et al. Sniff nasal inspiratory pressure in children. Pediatr Pulmonol 2000; 29: 468-75.

13. Hughes PD, Polkey MI, Moxham J, et al. Long-term recovery of diaphragm strength in neuralgic amyotrophy. Eur Respir J 1999; 13: 379-84.
14. Bianchi C, Baiardi P. Cough peak flows: standard values for children and adolescents. Am J Phys Med Rehabil 2008; 87: 461-7.

15. Tzeng AC, Bach JR. Prevention of pulmonary morbidity for patients with neuromuscular disease. Chest 2000; 118: 1390-6.

16. Similowski T, Fleury B, Launois S, et al. Cervical magnetic stimulation: a new painless method for bilateral phrenic nerve stimulation in conscious humans. $J$ Appl Physiol 1989; 67: 1311-8.

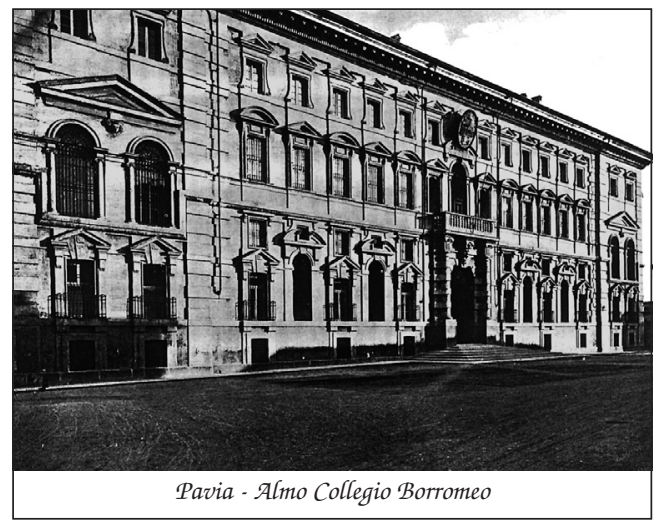

